\title{
Caracterização dos acidentes com máquinas agrícolas em rodovias federais no estado do Rio Grande do Sul
}

\author{
Characterization of accidents with farm machinery on federal highways in \\ the state of Rio Grande do Sul, Brazil
}

\author{
Deivielison Ximenes Siqueira Macedo $^{\mathrm{I}^{*}}$ Leonardo de Almeida Monteiro ${ }^{\mathrm{II}}$ \\ Viviane Castro dos Santos ${ }^{I}$ Daniel Albiero ${ }^{\text {II }}$ Carlos Alessandro Chioderoli ${ }^{I I}$
}

- NOTA -

RESUMO

Grande parte da área plantada do Rio Grande do Sul é destinada para o cultivo de culturas que necessitam do uso de máquinas agrícolas para seus tratos culturais. Todavia, o uso inadequado dessas máquinas propicia um maior número de acidentes, principalmente pela circulação das máquinas nas rodovias. Objetivou-se no trabalho caracterizar os acidentes com máquinas agrícolas ocorridos em rodovias federais no estado do Rio Grande do Sul, dando ênfase aos seus principais indicadores. Os registros dos acidentes foram obtidos através do Boletim de Acidentes de Trânsito da Polícia Rodoviária Federal, correspondentes ao período de janeiro de 2008 a setembro de 2011. Os indicadores dos acidentes avaliados foram tipo, causa, período do dia, rodovia em que ocorreu e a faixa etária dos acidentados. Foi feito o uso de estatística não paramétrica, sendo os dados avaliados através de análise de frequência e teste de independência do qui-quadrado. A causa mais frequente foi a falta de atenção, o tipo com maior percentual foi a colisão traseira, o periodo do dia com o maior número de acidentes foi o da tarde, o maior percentual de acidentados encontra-se na faixa etária entre 40 a 44 anos e as rodovias com maior número de acidentes foi a BR-285 e BR116. Recomenda-se que o trator só entre na rodovia seguindo as normas de trânsito e de segurança, e que o operador faça pequenas pausas quando estiver trabalhando em longos períodos.

Palavras-chave: trator, acidente de trânsito, operador de máquinas.

\section{ABSTRACT}

Large part of the planted Rio Grande do Sul area is intended for the cultivation of crops that require the use of agricultural machinery for its cultivation, but the inappropriate use of these machines provides a greater number of accidents, especially the movement of machinery on highways. The objective of the study is to characterize the agricultural machinery accidents occurred on federal roads in the state of Rio Grande do Sul emphasizing its main indicators. The records were obtained from the Traffic Accident Bulletin of the Federal Highway Police, covering the period of January 2008 to September 2011. The indicators evaluated were type of accidents, causes, time of day, highway where it occurred and the age of the injured. The use of nonparametric statistics was done and the data evaluated through frequency analysis and chi-square test of independence. The most frequent cause was the lack of attention, the kind with the highest percentage was the rear-end collision, the time of day with the highest number of accidents was the afternoon, the highest percentage of casualties is aged between 40 to 44 years and highways with the highest number of accidents was the BR-285 and $B R-116$. It is recommended that the tractor only get in the highway following the traffic rules and safety, and that the operator take short breaks when working for long periods.

Key words: tractor, traffic accident, machine operator.

O Rio Grande do Sul, de acordo com o último senso agropecuário realizado pelo IBGE (2007), é o estado com a maior frota de tratores da Região Sul, com 163.406 tratores, sendo responsável por aproximadamente $47 \%$ da frota total da região. Todavia, o uso inadequado dessas máquinas pode levar à ocorrência de acidentes.

A possibilidade da ocorrência destes acidentes com o trator se agrava ainda mais quando trafega em rodovias, já que, além do uso inadequado, outros fatores podem influenciar, como a velocidade incompatível da máquina com a via, a inexistência do sistema de amortecimento no trator e as configurações técnicas desproporcionais aos demais veículos,

IPrograma de Pós-graduação em Engenharia Agrícola, Universidade Federal do Ceará (UFC), 60451-970, Fortaleza, CE, Brasil. E-mail: derilsiqueira@hotmail.com.*Autor para correspondência.

IDDepartamento de Engenharia Agrícola, UFC, Fortaleza, CE, Brasil. 
interferindo no discernimento dos demais motoristas em situações corriqueiras (GKRITZA et al., 2010).

Estudos na área de segurança com conjuntos tratorizados, principalmente sobre ocorrência de acidentes, são muito importantes, porém verifica-se que no Brasil estes estudos ainda não são bastante difundidos, sendo raros os trabalhos na área, principalmente trabalhos que tenham foco em frequência, gravidade, características e causas de acidentes (DEBIASI, 2002). Quando se procura na literatura brasileira trabalhos envolvendo acidentes com tratores em rodovias, os dados diminuem bastante, chegando a ser escassos. De posse dessas informações, considerou-se necessário a realização da caracterização dos acidentes com máquinas agrícolas ocorridos nas rodovias federais no Rio Grande do Sul, informando os seus principais indicadores.

O trabalho foi realizado no Laboratório de Investigação de Acidentes com Máquinas AgrícolasLIMA, na Universidade Federal do Ceará-UFC. Os dados para a realização deste trabalho foram obtidos através da parceria do LIMA com a 16 Superintendência da Polícia Rodoviária Federal em Fortaleza, a partir do Boletim de Acidente de TrânsitoBAT, que é preenchido pelo policial rodoviário federal durante o registro da ocorrência do acidente.

No BAT, existem várias informações, todavia só algumas foram utilizadas como indicadores no presente trabalho, sendo elas: tipo de acidente, causa do sinistro, período do dia, faixa etária do operador acidentado e rodovia onde ocorreu o sinistro.

Com a finalidade de avaliar se as causas dos acidentes tiveram relação com os tipos destes, os indicadores foram reagrupados de forma diferente, sendo verificado 4 grupos de tipos de acidentes: colisão traseira, colisão lateral, colisão transversal e demais tipos de acidentes (atropelamento de pessoas, colisão frontal, colisão com objeto fixo, colisão com objeto móvel, danos eventuais, queda de veículos, saída de pista e tombamento). Já as causas foram divididas em dois grupos, ações inseguras (dormiu ao volante, falta de atenção, ingestão de álcool e ultrapassagem indevida) e o grupo das situações inseguras (defeito mecânico em veículos, distância insegura entre veículos, desobediência à sinalização e velocidade incompatível).

Foram avaliados 107 BAT que continham acidentes com máquinas agrícolas nas rodovias federais do estado do Rio Grande do Sul, num período de janeiro de 2008 a setembro de 2011, todavia não se teve a data precisa em relação ao dia e mês do sinistro, impossibilitando a comparação com as janelas de produção do estado.
Para análise estatística dos indicadores, fez-se o uso de estatística não paramétrica, sendo realizada análise de frequência dos acidentes, este método foi escolhido por melhor representar dados quantitativos. Para comparar as classes dos tipos de acidente com as classes das causas, foi realizado o teste de independência do qui-quadrado a $5 \%$, sendo a hipótese nula a inexistência de relação entre estes indicadores e a hipótese alternativa a existência de relação. Não foram realizadas medidas de dispersão, devido à inobservância destas avaliações em trabalhos relacionados a acidentes, já que se espera uma alta dispersão dos acidentes.

Foram verificados que 15 rodovias federais no Rio Grande do Sul tiveram acidentes no período supracitado pelo estudo, de acordo com a figura 1A, sendo a BR-285 a rodovia com maior incidência de acidentes, $18,69 \%$, seguida pela BR-116 com $17,76 \%$ e a BR-392, com frequência relativa de 11,21\%. Estes acontecimentos podem ser explicados pela extensão da rodovia no estado, pois, de acordo com o Ministério dos Transportes (2013), as extensões destas rodovias no estado são: BR-285 com $680,5 \mathrm{~km}$, BR-116 com $657,7 \mathrm{~km}$ e BR-392 com $729 \mathrm{~km}$, sendo que, quanto maior a rodovia, maior é a possibilidade de ocorrer acidentes.

Dos 107 acidentes, 13 acidentes não tiveram a idade do operador informada, os demais estão apresentados na figura 1B. A faixa etária com maior incidência de acidentados foi de 40 a 44 anos, com $15,96 \%$, seguida por 35 a 39 anos com 14,89\% e 45 a 49 anos 13,83\%. Esses dados são semelhantes às conclusões obtidas por AIKINS \& BARKAH (2012), os quais verificaram que, em Gana, a maioria dos acidentados tinha 40-49 anos, seguidos por 3039 anos. Esse aumento no número de acidentes nas faixas etárias mais elevadas, provavelmente, ocorre devido à experiência na profissão, levando ao excesso de confiança, por este motivo ocorrem pequenos descuidos, já que os operadores podem julgar desnecessárias algumas medidas de segurança que evitariam acidentes. A frequência de acidentados na faixa de 60 anos ou mais foi de 9,57\%, fato preocupante apesar da porcentagem inferior, pois GOODMAN et al. (1985), nos Estados Unidos, verificaram que quase $41 \%$ das mortes relacionadas com tratores foram com operadores acima dos 60 anos, os pesquisadores atribuem estas mortes à deficiência fisiológica, proveniente da idade e que pessoas idosas, quando sofrem traumas graves podem ter menor probabilidade de sobrevivência.

Os tipos de acidentes mais frequentes, segundo figura $1 \mathrm{C}$, foram a colisão traseira com 


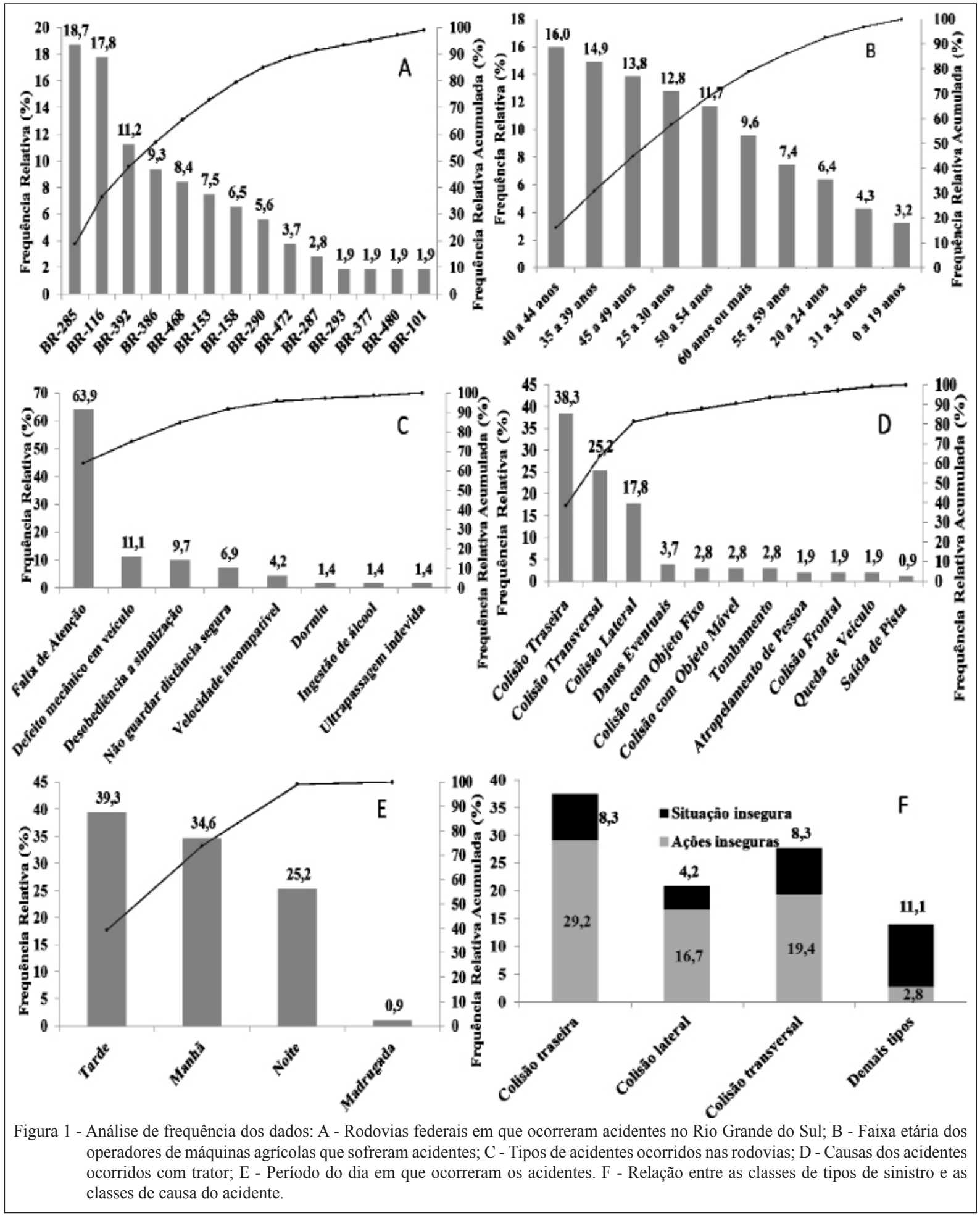

$38,32 \%$, seguido de colisão transversal com $25,83 \%$ e colisão lateral com $17,76 \%$. O fato de ocorrer a colisão traseira está associado à baixa velocidade de locomoção do trator, sendo de 15 a $20 \mathrm{~km}$, muito abaixo das velocidades atingidas pelos outros veículos e permitidas pelas vias, impossibilitando, muitas vezes, que o veículo mais rápido pare antes de colidir com o trator. GKRITZA et al. (2010) realizaram estudos no sistema rodoviário do estado de Iowa nos Estados Unidos e verificaram que a colisão traseira 
foi o tipo de acidente com maior índice dentre os tipos de colisões com tratores.

Dos 107 boletins verificados, 35 não tinha uma causa específica, não sendo considerados para estudo de causa do sinistro e nem para relação com tipo de acidente. Avaliando a figura 1D, observase que a principal causa dos acidentes foi a falta de atenção, com quase $64 \%$ de ocorrência; na sequência, defeito mecânico com 11,11\% e desobediência à sinalização com quase $10 \%$. SCHLOSSER et al. (2002) apontam como possíveis fatores responsáveis pela falta de atenção dos operadores as longas jornadas de trabalho, a fadiga dos operadores e os tratores ergonomicamente mal projetados para os operadores de máquinas agrícolas brasileiros.

De acordo com a figura 1E, o período do dia que mais ocorreu acidentes foi o da tarde, com $39,25 \%$, depois o período da manhã, com $34,58 \%$, a noite, com $25,23 \%$ e por último a madrugada, com $0,93 \%$. Geralmente, empresas possuem dois turnos de trabalho, um começando de manhã e terminando à tarde e o outro começando à tarde e terminando à noite. Neste processo de ir e voltar do serviço, possivelmente, encontra-se o tráfego maior dos tratores nas rodovias. Já que muitas vezes existe a necessidade de locomover o trator de uma fazenda para outra, no início e no final de um expediente, possivelmente, por este motivo, no período da tarde, foi encontrado o maior número de acidentes.

Para o teste de qui-quadrado sobre a relação entre as classes de tipo e de classes de causa, o valor calculado foi de 14,72762, maior que o valor tabelado, 12,5916, rejeitando-se a hipótese nula. Para este trabalho, ouve relação entre as classes de tipos e classes de causa, ou seja, pelo menos uma classe de causa interferiu sobre a ocorrência dos tipos de acidentes, possivelmente, seja a classe de ações inseguras que tenha interferido como é apresentado na figura $1 \mathrm{~F}$.
O principal tipo de acidente é a colisão traseira, e a principal causa a falta de atenção, sendo prudente o uso de trator nas vias públicas somente se for necessário e de acordo com as normas de trânsito vigente e de segurança. Também seria necessário que operadores tenham pequenas pausas após horas de serviço, diminuindo sua fadiga e consequentemente seu déficit de atenção.

\section{REFERÊNCIAS}

AIKINS, S.H.M.; BARKAH, N.K. Tractor operators and passengers' perception about tractor safety in Kumasi, Ghana. Global Institute for Research \& Education, v. 1. 2012. Disponível em: <http:// www.gifre.org/admin/papers/gjedt/1213-6-13.pdf >. Acesso em: 03 jun. 2013.

DEBIASI, H. Diagnóstico dos acidentes de trabalho e das condições de segurança na operação de conjuntos tratorizados. 2002. 290f. Dissertação (Mestrado em Engenharia Agrícola) Universidade Federal de Santa Maria, Santa Maria - RS.

GOODMAN, R.A. Fatalites associated with farm tractor injuries: an epidemiologic study, v.100. n.3. p.329-332, 1985. Disponível em: <http://www.ncbi.nlm.nih.gov/pmc/articles/PMC1424762/>. Acesso em: 02 jun. 2013.

GKRITZA, K. et. al. An empirical analysis of farm vehicle crash injury severities on Iowa's public Road system. Accident Analysis and Prevention, v.42, p.1392-1397, 2010. Disponível em: <http:// www.sciencedirect.com/science/article/pii/S0001457510000679>. Acesso em: 08 ago. 2012.

INSTITUTO BRASILEIRO DE GEOGRAFIA E ESTATÍSTICA (IBGE). Censo Agropecuário 2006 (resultados preliminares). Rio de Janeiro, 2007. 142p.

MINISTÉRIO DOS TRANSPORTES, Rodovias do estado do Rio Grande do Sul. Disponível em: <http://www2.transportes. gov.br/bit/01-inicial/01-estadual/estados/port/rs.htm>. Acesso em: 08 maio 2013.

SCHLOSSER, J.F. et al. Caracterização dos acidentes com tratores agrícolas. Ciência Rural, v.32, n.6, p.977-981, 2002.v. Disponível em: <http://www.scielo.br/pdf/cr/v34n3/a19v34n3.pdf>. Acesso em: 21 set. 2012. 